\title{
Building Early Academic Career Capacity through Mentoring
}

Michelle Cleary, PhD, RN

Debra Jackson, RN, PhD FACN

Jan M. Sayers, PhD, RN

Violeta Lopez, PhD, RN

A strong and resilient academic workforce is essential if we are to adequately prepare future generations of nurses. Currently, there is an international shortage of nursing faculty (McDermid, Peters, Jackson, \& Daly, 2012), and these shortages are expected to grow (Reid, Hinderer, Jarosinski, Mister, \& Seldomridge, 2013). Research findings suggest that there are a number of challenges for nurses transitioning from the health sector into academic life (Halcomb et al., 2015; Halcomb, Andrew, Peters, Salamonson, \& Jackson, 2010; McDermid, Peters, Daly, \& Jackson, 2013). One of these challenges is the need to develop research expertise and become an active researcher (Jackson, 2008b; Jackson, Peters, Andrew, Salamonson, \& Halcomb, 2011). Associated with this is the need to form productive collaborations and relationships within and without of the academic environment (Cleary \& Hunt, 2010; Horsfall, Cleary, \& Hunt, 2011).

Mentoring can be a valuable strategy for facilitating the development of new faculty. The importance of mentoring for nurses both academically and clinically is well recognized, and has been associated with positive growth and the development of leadership skills (Jackson et al., 2015; Leggat, Balding, \& Schiftan, 2015; McCloughen, O'Brien, \& Jackson, 2009). It is considered fundamental to establishing and nurturing an academic career and dealing with the constantly changing demands evident in academic life.

The shortage in the academic workforce has implications for meeting the demands of nursing research and leadership (McDermid et al., 2012). Given that nursing is an academic discipline which is dependent on evidence-based practice with a need to generate, disseminate, and apply evidence through education and advanced scholarship, a critical need to build research capacity has been identified (Jackson, 2008b; Reid et al., 2013). Faculty life can be demanding and upcoming academics face a number of challenges (Cleary, Walter, Halcomb, \& Lopez, 2016) particularly in relation to managing demands whilst establishing a research profile (McDermid et al., 2013). Research is necessary for the profession to provide the best possible care to patients and clients, and to advance evidence-based practice (Reid et al., 2013). Whilst the benefits of mentoring are well established (Huang, Weng, \& Chen, 2016; McCloughen, O’Brien, \& Jackson, 2006; McCloughen, O’Brien, \& Jackson, 2010); in some ways it has been embraced quite uncritically (Green \& Jackson 2014). It is important to recognize it is not a panacea, and there are potential challenges and pitfalls that should be considered (Green \& Jackson, 2014; Jackson et al., 2015).

In the academic environment success is measured by a range of outcomes including (but not limited to) publications and citations; collaboration and networking; completed supervision of higher degree research students; successful grant applications and other peer esteem measures (Cleary, Sayers, \& Watson, 2016). Meeting these outcomes requires strategic planning, and goal setting underpinned by drive, energy and determination. However, it is unrealistic to assume that the nurse transitioning into academic life will achieve these independently. The transition to academia, requires adjustments as with any new role, and an appropriate network of support; and including the support 
of a mentor during this period and beyond can be pivotal (Cleary, Horsfall, \& Jackson, 2011; McCloughen et al., 2009).

For transitioning faculty, decision-making needs to focus on the individual's career trajectory, the development of goals and how achieving them can be supported (Hemmings, Hill, \& Sharp, 2013). Effective mentoring and belonging to an inclusive and productive research group are key factors influencing research capacity and outcomes (Debowski, 2012). Early career academics are potential future research leaders and change agents not merely within academia but also through their involvement in health settings and professional practice where they may be role models and influential through their leadership, research and collaborative partnerships.

Effective mentoring can foster the socialization of the new academic as well as providing support and knowledge development (Ferguson \& Wheat, 2015). Mentoring can take many forms, and may be formal or informal, but however it is constructed it is an inclusive interpersonal process aimed at learning and growth (Cleary \& Horsfall, 2015). Often mentors are role models, and the relationship between mentor-mentee is based on the sharing of knowledge, expertise and professional experience; questions can be clarified and information shared to better support the new academic and ensure a nurturing learning environment (Cleary et al., 2011).

Formats for mentoring differ - sometimes, dyads may be the method of choice although group mentoring is also effective (Cook, Bahn, \& Menaker, 2010). In the traditional mentoring dyad the mentor and mentee will work together to establish, monitor, and review goals. The mentee may choose the mentor or may have their mentor chosen for them. However this can be problematic as there is some evidence that imposed relationships do not work, and like any other relationship, mutual attraction is an element of effective mentoring (Jackson, 2008a); and so therefore allowing self-selection, where mentees choose their own mentors can be more successful (McDonald, Mohan, Jackson, Vickers, \& Wilkes, 2010). In addition, numbers of available mentors may be inadequate and those that are available may be limited by the constraints of competing priorities, responsibilities and time (Pololi \& Evans, 2015). Speed mentoring offers different opportunities to be mentored and involves mentees having a limited period of time (e.g. 10 minutes) to talk with a mentor about a specific subject before moving on to the next mentor (Serwint, Cellini, Spector, \& Gusic, 2014). This may be useful when seeking input in a specific area (such as from senior staff) however speed mentoring does not denote the relational aspects associated with classic mentoring, and can only really generate interest and understanding so may not necessarily meet needs for support on an ongoing basis.

In group mentoring one mentor may work with a group of mentees. Similar to the mentee in the dyad, mentees within the group may establish and drive the agenda for career advice and support to develop individual capabilities (Meister \& Willyerd, 2010). A primary goal of group mentoring is the alignment of individual mentee values with professional decisions (Pololi \& Evans, 2015). Group mentoring programs can be tailor made to the groups' needs. There are many approaches, and group mentoring may be faculty facilitated and specific topics may be nominated and prioritized by participants. Such models can provide group members the time and space to share experiences and knowledge on a peer-to-peer basis and network in a relaxed atmosphere (Chen, Sandborg, Hudgins, Sanford, \& Bachrach, 2016).

Interdisciplinary mentoring is another model that has been successfully implemented to assist earlycareer faculty in achieving external research funding. In these models, senior faculty-led interdisciplinary teams may not only provide mentoring but also provide opportunities for junior faculty to develop skills in grant productivity, academic success and network building (Libby et al., 
2016). Studies reporting interdisciplinary team mentoring have indicated they can be helpful for career development, building social networks, and offer different tastes to career opportunities and challenges from different disciplinary groups (Guise, Geller, Regensteiner, Raymond, \& Nagel, 2016).

Effective and nurturing collegial relationships including mentoring is essential for the future of nursing (McNamara et al., 2014), and for building leadership development capacity (McCloughen, O'Brien, \& Jackson, 2011; Nick et al., 2012). The functional outcomes of mentoring include enhanced integration into academic life, development of teaching, scholarship, and governance skills, as well as leadership growth (Nick et al., 2012). Institutions with established mentoring programs report positive outcomes such as improved morale, better career satisfaction, increased self-confidence, improved professional development/career opportunities, increased scholarly outputs, improved recruitment and retention, positive peer relations/enhanced commitment, better teamwork and improved productivity (Nick et al., 2012; Reid et al., 2013).

While some elements may be difficult to measure, mentorship outcomes which can be easily measured include scholarly outputs such as grants and publications, job satisfaction and commitment, career opportunities, positive peer relations, career recognition and success, and improved skill competence and development (Reid et al., 2013). Pivotal to the outcomes of mentoring relationships is the capacity of mentees to better understand themselves, their professional role and values and how these may influence their career choices, leadership and capacity for collaboration (Pololi \& Evans, 2015). Another important consideration in this relationship is the recognition of organizational culture including its vision, values, norms, systems and resources available for a successful mentoring process (Manson, 2016).

Mentors have an active role to play but in uncritically embracing mentoring, we often forget that mentors may also need support while working on a regular ongoing basis with mentees. Not all mentoring is a positive experience; there can be difficulties (Green \& Jackson, 2014), and toxic mentoring is a recognized concern in the literature (Darling, 1985), and this may be a problem, especially where relationships are imposed. Mentors may need training and support, protected time as well formal feedback and evaluation from the mentee and the organization (Sood, Tigges, \& Helitzer, 2016). Given current faculty shortages, current workloads and time constraints, and the emphasis on collaboration, there may be an increase in group mentoring as the available pool of mentors diminishes.

To conclude, mentoring is a key strategy that can provide essential support to the early career academic. Establishing the next generation of academic leaders, innovators and experts is essential given the challenges in recruiting and retaining suitably qualified staff (Brody et al., 2016; McDermid et al., 2012). Developing a mentoring relationship can facilitate new academics in identifying career goals and priorities that can support their career trajectory. Mentoring can also support new academics to understand the importance of collaborative work, share experiences, foster an appreciation for diversity, role model mentorship, build strengths and develop synergies between experienced and novice faculty. 
References

Brody, A. A., Edelman, L., Siegel, E. O., Foster, V., Bailey, D. E., Bryant, A. L., \& Bond, S. M. (2016). Evaluation of a peer mentoring program for early career gerontological nursing faculty and its potential for application to other fields in nursing and health sciences. Nursing Outlook, 64(4), 332338. doi:10.1016/j.outlook.2016.03.004.

Chen, M. M., Sandborg, C. I., Hudgins, L., Sanford, R., \& Bachrach, L. K. (2016). A Multifaceted Mentoring Program for Junior Faculty in Academic Pediatrics. Teaching and Learning in Medicine, 28(3), 320-328. doi:10.1080/10401334.2016.1153476.

Cleary, M., \& Horsfall, J. (2015). Coaching: Comparisons with Mentoring. Issues in Mental Health Nursing, 36(3), 243-245. doi:10.3109/01612840.2015.1002344.

Cleary, M., Horsfall, J., \& Jackson, D. (2011). Mental health nursing: Transitions from practice roles to academia. Perspectives in Psychiatric Care, 47(2), 93-97. doi:10.1111/j.1744-6163.2010.00280.x.

Cleary, M., \& Hunt, G. E. (2010). Building community engagement in nursing. The Journal of Continuing Education in Nursing, 41(8), 344-345. doi:10.3928/00220124-20100726-04.

Cleary, M., Sayers, J., \& Watson, R. (2016). Essentials of building a career in nursing research. Nurse Researcher, 23(6), 9-13. doi:10.7748/nr.2016.e1412.

Cleary, M., Walter, G., Halcomb, E., \& Lopez, V. (2016). An examination of envy and jealousy in nursing academia. Nurse Researcher, 23(6), 14-19. doi:10.7748/nr.2016.e1405.

Cook, D. A., Bahn, R. S., \& Menaker, R. (2010). Speed mentoring: An innovative method to facilitate mentoring relationships. Medical Teacher, 32(8), 692-694. doi:10.3109/01421591003686278.

Darling, L. A. W. (1985). What to do about toxic mentors. Journal of Nursing Administration, 15(5), 43-45. doi:10.1097/00005110-198505000-00008.

Debowski, S. (2012). The New Academic: A Strategic Handbook: A Strategic Handbook. UK: McGrawHill Education.

Ferguson, H., \&Wheat, K. L. (2015). Early career academic mentoring using Twitter: The case of \#ECRchat. Journal of Higher Education Policy and Management, 37(1), 3-13.

doi:10.1080/1360080X.2014.991533.

Green, J., \& Jackson, D. (2014). Mentoring: Some cautionary notes for the nursing profession. Contemporary Nurse, 47(1-2), 79-87. doi:10.1080/10376178.2014.11081909.

Guise, J. M., Geller, S., Regensteiner, J. G., Raymond, N., \& Nagel, J. (2016). Team Mentoring for Interdisciplinary Team Science: Lessons From K12 Scholars and Directors. Academic Medicine. doi:10.1097/acm.0000000000001330

Halcomb, E., Jackson, D., Daly, J., Gray, J., Salamonson, Y., Andrew, S., \& Peters, K. (2015). Insights on leadership from early career nurse academics: Findings from a mixed methods study. Journal of Nursing Management, 24(2), E155-E163. doi:10.1111/jonm.12317.

Halcomb, E. J., Andrew, S., Peters, K., Salamonson, Y., \& Jackson, D. (2010). Casualisation of the teaching workforce: Implications for nursing education. Nurse Education Today, 30(6), 528-532. doi:10.1016/j.nedt.2009.10.022. 
Hemmings, B., Hill, D., \& Sharp, J. (2013). Research Experiences of Staff within a Specialist UK Higher Education Institution: Challenges, opportunities and priorities. Tertiary Education and Management, 19(1), 52-67. doi:10.1080/13583883.2012.742924.

Horsfall, J., Cleary, M., \& Hunt, G. E. (2011). Developing partnerships in mental health to bridge the research-practitioner gap. Perspectives in Psychiatric Care, 47(1), 6-12. doi:10.1111/j.17446163.2010.00265.x.

Huang, C. Y., Weng, R. H., \& Chen, Y. T. (2016). Investigating the relationship among transformational leadership, interpersonal interaction and mentoring functions. Journal of Clinical Nursing, 25, 2144-2155. doi:10.1111/jocn.13153.

Jackson, D. (2008a). Editorial: Random acts of guidance: personal reflections on professional generosity. Journal of Clinical Nursing, 17(20), 2669-2670. doi:10.1111/j.1365-2702.2008.02346.x.

Jackson, D. (2008b). Servant leadership in nursing: A framework for developing sustainable research capacity in nursing. Collegian, 15(1), 27-33. doi:10.1016/j.colegn.2007.10.001.

Jackson, D., Peters, K., Andrew, S., Daly, J., Gray, J., \& Halcomb, E. (2015). Walking alongside: A qualitative study of the experiences and perceptions of academic nurse mentors supporting early career nurse academics. Contemporary Nurse, 51(1), 69-82. doi:10.1080/10376178.2015.1081256.

Jackson, D., Peters, K., Andrew, S., Salamonson, Y., \& Halcomb, E. J. (2011). "If you haven't got a PhD, you're not going to get a job": The PhD as a hurdle to continuing academic employment in nursing. Nurse Education Today, 31(4), 340-344. doi:10.1016/j.nedt.2010.07.002.

Leggat, S. G., Balding, C., \& Schiftan, D. (2015). Developing clinical leaders: The impact of an action learning mentoring programme for advanced practice nurses. Journal of Clinical Nursing, 24(11-12), 1576-1584. doi:10.1111/jocn.12757.

Libby, A. M., Hosokawa, P. W., Fairclough, D. L., Prochazka, A. V., Jones, P. J., \& Ginde, A. A. (2016). Grant success for Early-career faculty in Patient-oriented Research: Difference-in-differences evaluation of an interdisciplinary mentored research training program. Academic Medicine. doi:10.1097/acm.0000000000001263

Manson, S. M. (2016). Early-stage investigators and institutional interface: Importance of organization in the mentoring culture of today's universities. AIDS and Behavior, 20 Suppl 2, 304310. doi:10.1007/s10461-016-1391-0.

McCloughen, A., O'Brien, L., \& Jackson, D. (2010). More than vision: Imagination as an elemental characteristic of being a nurse leader-mentor. Advances in Nursing Science, 33(4), 285-296. doi:10.1097/ANS.0b013e3181fb2e62.

McCloughen, A., O’Brien, L., \& Jackson, D. (2006). Positioning mentorship within australian nursing contexts: A literature review. Contemporary Nurse, 23(1), 120-134.

doi:10.5172/conu.2006.23.1.120.

McCloughen, A., O’Brien, L., \& Jackson, D. (2009). Esteemed connection: Creating a mentoring relationship for nurse leadership. Nursing Inquiry, 16(4), 326-336. doi:10.1111/j.14401800.2009.00451.x.

McCloughen, A., O'Brien, L., \& Jackson, D. (2011). Nurse leader mentor as a mode of being: Findings from an Australian hermeneutic phenomenological study. Journal of Nursing Scholarship, 43(1), 97104. doi:10.1111/j.1547-5069.2010.01377.x. 
McDermid, F., Peters, K., Jackson, D., \& Daly, J. (2012). Factors contributing to the shortage of nurse faculty: A review of the literature. Nurse Education Today, 32(5), 565-569.

doi:10.1016/j.nedt.2012.01.011.

McDermid, F., Peters, K., John Daly, J., \& Jackson, D. (2013). 'I thought I was just going to teach': Stories of new nurse academics on transitioning from sessional teaching to continuing academic positions. Contemporary Nurse, 45(1), 46-55. doi:10.5172/conu.2013.45.1.46.

McDonald, G., Mohan, S., Jackson, D., Vickers, M. H., \& Wilkes, L. (2010). Continuing connections: The experiences of retired and senior working nurse mentors. Journal of Clinical Nursing, 19(23-24), 3547-3554. doi:10.1111/j.1365-2702.2010.03365.x.

McNamara, M. S., Fealy, G. M., Casey, M., O’Connor, T., Patton, D., Doyle, L., \& Quinlan, C. (2014). Mentoring, coaching and action learning: Interventions in a national clinical leadership development programme. Journal of Clinical Nursing, 23(17-18), 2533-2541. doi:10.1111/jocn.12461.

Meister, J. C., \& Willyerd, K. (2010). Mentoring millennials. Harvard Business Review, 88(5), 68-72.

Nick, J. M., Delahoyde, T. M., Del Prato, D., Mitchell, C., Ortiz, J., Ottley, C., \& Siktberg, L. (2012). Best Practices in Academic Mentoring: A Model for Excellence. Nursing Research and Practice, 2012, 9.

Pololi, L. H., \& Evans, A. T. (2015). Group peer mentoring: An answer to the faculty mentoring problem? A successful program at a large academic department of medicine. Journal of Continuing Education in the Health Professions, 35(3), 192-200. doi:10.1002/chp.21296.

Reid, T. P., Hinderer, K. A., Jarosinski, J. M., Mister, B. J., \& Seldomridge, L. A. (2013). Expert clinician to clinical teacher: Developing a faculty academy and mentoring initiative. Nurse Education in Practice, 13(4), 288-293. doi:10.1016/j.nepr.2013.03.022.

Serwint, J. R., Cellini, M. M., Spector, N. D., \& Gusic, M. E. (2014). The value of speed mentoring in a pediatric academic organization. Academic Pediatrics, 14(4), 335-340.

doi:10.1016/j.acap.2014.02.009.

Sood, A., Tigges, B., \& Helitzer, D. (2016). Mentoring Early-career faculty researchers is Importantbut first "Train the Trainer". Academic Medicine, doi:10.1097/acm.0000000000001264. 